\title{
KANT'S PROBLEM OF CAUSALITY AND THE DING-AN-SICH
}

\section{John Visintainer \\ Marquette University}

Kant's Copernican Revolution in philosophy was mainly a response to the thought of the British Empiricists. He wanted to ground certain concepts and precepts that the British Empiricists had nearly destroyed. We can say that the Copernican Revolution in philosophy addressed probems with the ego, justice and the Good, and so on. The aspect of the Copernican Revolution with which I am concerned in this essay is Kant's view of the necessity of cause and effect relationships. My concern in this essay is to show that Kant is not committed to the problem of transcendental causality. In short, some philosophers have claimed that Kant must be committed to holding the following contradiction: There is no causal agency known outside of the realm of categorial judgment, yet appearances must be caused by things in themselves, which are not categorially judged. Kant, in one breath, states that judgements of cause and effect hold only of appearances, while stating at other times that things in themselves must be the cause of our appearances.

I will argue that Kant can escape this difficulty. In order to remove the apparent contradiction, I will show that Kant can claim that things in themselves need not be the cause of our appearances. Rather, they provide the ground for appearances. Even though Kant does indeed sometimes speak as though things in themselves should be the cause of appearances, it will be shown that, ultimately, he is not committed to this language. Therefore, Kant will not be committed to the contradiction.

First, I should like to expose the problem as it is in the Critique of Pure Reason. Kant states in the Transcendental Deduction section of the Critique of Pure Reason: "All attempts to derive these pure concepts of the understanding ['cause and effect' is a pure concept of the understanding] from experience, and so to ascribe to them a merely empirical origin, are entirely vain and useless." From where are the pure concepts of the understanding derived? Kant states, "...I maintain that the categories...are

1 Immanuel Kant. Critique of Pure Reason. A112. 
nothing but the conditions of thought in a possible experience just as space and time are the conditions of intuition for that same experience. They are fundamental concepts by which we think objects in general for appearances [my italics]."2

As has already been established in the Critique of Pure Reason, the human subject is given appearances and appearances only. "...The thing in itself...is not known, and cannot be known...and in experience no question is ever asked in regard to it." 3 It is the case that persons are not free to condition the things in themselves with the pure intuitions of space and time. Rather, the person receives objects in space and time because this is just the way in which the manifold is always presented to the human subject. Persons are only privy to appearances. They are not privy to the thing in itself. Now, to derive any knowledge about appearances, persons must make synthetic judgments. The very condition of knowledge about appearances can only come about by way of the synthetic judgment.

In addition to this, Kant asserted that the thing in itself cannot be the object of experience. Only appearances are judged synthetically. Once the thing in itself is made present to the human subject, it is no longer the thing in itself. It is an appearance, because it is given in space and time. Appearances come with extension, and they come in time. This spatio-temporal ordering cannot be known of the thing in itself.

Two places we may examine in order to expose the Kantian notion of synthetic judgment are the Transcendental Analytic and the Second Analogy of Experience.

We begin with the Transcendental Analytic. At A77, Kant states,

"Space and time contain a manifold of pure $a$ priori intuition, but at the same time are conditions of the receptivity of our mind-conditions under which alone it can receive representations of objects, and, which therefore must also always affect the concept of these objects. But if this manifold is to be known, the spontaneity of our thought requires that it be gone through in a certain way, taken up, and connected. This act I name synthesis."4

\footnotetext{
2 Ibid., A111.

3 Ibid., A30.

4 Ibid., A77.
} 
There is a great amount of importance in this one statement. First, we consider that the human subject is presented with a manifold. The manifold can be seen as having in itself nothing in the way of knowledge to offer to the human subject. Once presented with the manifold, the human subject spontaneously 'takes up' the manifold. In this 'taking up', there is then made connections. Kant seems to be saying that connection per se comes from the human subject. This follows because the manifold is without connection. Kant later mentions affinity, of course. However, this affinity does seem quite different from actual connection.

Now, the human being engages in synthesis. In regard to synthesis, Kant states, "Synthesis in general, as we shall hereafter see, is the mere result of the power of imagination, a blind but indispensable function of the soul, without which we should have no knowledge whatsoever...."5

There can be no knowledge without synthesis. The human subject is presented with the manifold at first. While present to the manifold and to only the manifold, the person is completely devoid of knowledge. Of course, at this point the appearances that are given by the manifold are not without condition. The human subject is conditioning the appearances with the pure intuitions of space and time. So, in the manifold there is still no knowledge, but the appearances come to us in some temporal order. The appearances follow one another in time, or they arise at the same time. Furthermore, the appearances always come extended. This is the function of the pure intuition of space.

Persons are privileged to the appearances, and persons make synthetic judgments about the appearances. The synthetic judgment of "cause and effect' is one such judgment. It is in the third set of categories that we find the category called 'Of Causality and Dependence (cause and effect)'. Kant's placement of the notion of cause and effect directly here in the categories leads us to believe that judgments of cause and effect must, as a rule, be seen by Kant to be purely phenomenal. This follows from the fact that the phenomenal realm is the realm in which knowledge is adherent. So, we anticipate that Kant will indeed explicitly state that knowledge of cause and effect is a function of human synthesis.

Our anticipation is justified in the Second Analogy of Experience. At the outset of the Second Analogy, Kant states:

5 Ibid., A78. 
"I perceive that appearances follow one another, that is, that there is a state of things at one time the opposite of which was in the preceding time. Thus I am really connecting two perceptions in time. Now connection is not the work of mere sense and intuition, but is here the product of a synthetic faculty of imagination, which determines inner sense in respect of time-relation. ${ }^{6}$

As we know from the discussion of the categories, when Kant here claims that connection is the product of the synthetic faculty of imagination, we know that this means that the very act of connection itself is the product of the human subject. The connection is not adherent in the transcendental object.

Kant voices his concern over the fact that connection strictly is a product of the synthetic faculty of imagination:

"But imagination can connect these two states in two ways, so that either the one or the other precedes in time. For time cannot be perceived in itself, and what precedes and what follows cannot, therefore, by relation to it, be empirically determined in the object. I am conscious only that my imagination sets the one state before and the other after, not that the one state precedes the other in the object. In other words, the objective relation of appearances that follow upon one another is not to be determined through mere perception. In order that this relation be known as determined, the relation between the two states must be so thought that it is thereby determined as necessary which of them must be placed before, and which of them after, and that they cannot be placed in the reverse relation. But the concept which carries with it a necessity of synthetic unity can only be a pure concept that lies in the understanding, not in perception; and in this case it is the concept of the relation of cause and effect " 7

6 Ibid., B233.

7 Ibid., B233-B234 
Kant is concerned with how it is possible for the human subject to synthesize causal judgments in the world correctly. This is obvious from the fact that Kant claims that time is a product of the pure intuition. Because, if time is a product of the pure intuition, then it could be possible that persons could make judgments about phenomenal objects that do not correspond to how the noumenal objects truly are. To wit, the human subject is always intuiting time relations of succession. So, how do we know that our judgments of time succession correspond to the way things really are?

The answer is that the experience that we humans have that is synthetic must somehow have, as its ground, the thing in itself. As Wayne Waxman states, "If any objective necessity at all is to be salvaged for the temporal order of representations, it can only be through relation to the thing in itself." 8 Of course, this objective necessity of the temporal order of representations is extremely problematic. We cannot know anything about the noumenal realm at all. The very derivation of this objective necessity is what Kant is looking for in the Second Analogy, and any further discussion of this particular problem is certainly beyond the scope of this paper.

There are moments when Kant seems to ascribe the same type of cause and effect judgments to the things in themselves that he ascribes to the appearances. I assert that the reason for this is that Kant is trying to give the appearance some sort of ground in the thing in itself. We find in Section 6 of the Antinomy of Pure Reason,
“...To say that [objects of the senses] exist prior to all my experience is only to assert that they are to be met with if, starting from perception, I advance to that part of experi- ence to which they belong. The cause of empirical condi- tions of this advance...is transcendental, and is therefore necessarily unknown to me." 9

Here, Kant is forwarding two important points. First, we find Kant claiming that there is, in fact, transcendental causality. Second, Kant clearly claims that whatever it is which is in the realm of the transcendental is not knowable.

\footnotetext{
8 Wayne Waxman. "Kant's Analogies." The Review of Metaphysics. Sept. 1993 , Vol. 47, No.1.

9 Ibid., A496.
} 
In the Amphiboly of Concepts of Reflection we find, "Understanding... does...think for itself an object in itself, but only as transcendental object, which is the cause of appearance and therefore not itself appearance...."10 The transcendental object seems to have an affect on the "faculty of knowledge' and the 'understanding'. However, cause and effect relationships can never be known in the transcendental. Transcendental matters can only be thought. The Kantian claim will be that 'cause and effect' is a function of synthesis. 'Cause and effect' has its place insofar as pertaining to how the understanding synthesizes phenomenal objects.

This is where the apparent contradiction arises. Kant claims at one time that the appearance is the only object that can be taken by the human subject for synthesis by way of the categories. In summary, persons are given appearances. The appearances come in space and time, because the understanding can only have objects in space and time. The human subject is not free to experience things apart from space and time. Synthetic judgments are always of appearances. When Kant speaks of a known cause by the transcendental object, the apparent contradiction is this: Kant seems to say that the Kant knows that the transcendental is the cause of the appearance. However, 'cause and effect' must be, as a rule, a synthetic judgment made of the appearance.

We now move to the criticism of Kant put forward by Peter Strawson in The Bounds of Sense. Strawson's project is to expose an incoherence in Kantian philosophy regarding causality, and we shall follow his line of argumentation through the relevant sections of Strawson's book.

First, Strawson neatly summarizes the whole of Kant's position on appearances and things in themselves.

"Knowledge through perception of things existing independently of perception, as they are in themselves, is impossible. For the only perceptions which could yield us any knowledge at all of such things must be the outcome of being affected by those things; and for this reason such knowledge can be knowledge only of those things as they appear...and not of those things as they really are or are in themselves." II

10 Ibid., A288.

11 Peter Strawson. The Bounds of Sense. p.250. 
This is a fine summation of the noumenal/phenomenal distinction on the whole. However, I would like to make one point. It seems that Strawson is blatantly setting the Kantian position in such a way as to attack it. I point to the fact that Strawson uses the term 'affects' in regard to the agency that the thing in itself has toward the phenomenon. For the purposes of my essay, we must allow that Kant is not condemned, yet, to this language. The Kantian doctrine, on the whole, may still find a way to elude the need to use such causal terms in regard to the relationship between noumena and phenomena. We find the problem already in hand with Strawson, but, nevertheless, we continue through Strawson's argument.

Strawson goes on to give two concepts which he sees as inherent to the phenomena/noumena split-the concept of identity of reference and the concept of the 'corrected view'. Strawson states,
"When it is said that a thing appears to be thus-and-so, but really is not, it seems to be implied that there are two dif- ferent standpoints from which it would be natural to make different and incompatible judgments about the same thing. ...The standpoints...must have something in common, so that there is some way...of securingidentity of reference to the thing which is judged." 12

Strawson concludes from this, "...our sensible experience is the causal outcome of our being affected by the objects we say we perceive."13

Strawson is extremely reticent to give examples here to explain his position, so I shall provide one of my own. Consider the classic example of the stick that appears to be bent when half of it is immersed into water. When the stick is observed to be bent, persons tend to apply Strawson's first concept-the identity of reference. The observer must have in mind two ideas. He or she has in mind, first, the idea of the 'original' stick. This is the 'straight' stick. Then, the observer contemplates the 'second' stick. It is 'bent'. (It seems inappropriate to say it 'appears' bent at this point.) Now, the observer applies the concept of identity of reference. In doing so, the observer claims that the first stick with its properties and the second stick with its properties are actually the same stick. I grant that Strawson is

\footnotetext{
12 The Bounds of Sense. pp. 250-251.

13 Ibid.
} 
correct insofar as his notion of the identity of reference does become applied by human being all the time in 'common-sense'.

Now, Strawson combines the concept of identity of reference with the concept of the corrected-view. On Strawson's account, the corrected-view comes about when an observer has a privileged position to a particular object of consciousness. 14 It seems that this privilege could occur when one person corrects another person or when one person corrects himself or herself. Let us again take the example of the stick. It is practically a rule of common-sense to say that the stick is not really bent when it is in the water. We purport the corrected-view. We say that the stick appears to be bent when it is in fact not really bent.

Strawson proceeds toward his conclusion. He asks, what can be the function that makes the corrected-view in light of the fact that we all agree that the thing observed is not the thing as it actually is? Strawson claims that it must be intuition for Kant. Strawson states that the 'view' of the object of the corrected-view is not a view at all. In a word, the correctedview is never strictly a view in the sense that it is never sensible.15 The corrected-view can only come from a further synthetic judgment.

The question remains, how do we know that our synthetic judgment is veridical? In other words, how do persons arrive at the correct synthetic judgment? For Strawson, the only way that persons can ever have veridical experience is because appearances are caused by transcendental things. There can be no absolute veridical knowledge without the appearance being caused by the thing in itself. Otherwise, the appearance would be pure phantom. There would be no certainty in our synthetic judgment that the crooked stick is not a veridical experience. What would be the basis for judging the crooked stick to be non-veridical? The answer is there would be no basis for judging the crooked stick as illusion. Our judgments remain capricious for Strawson without the causal agency of the thing in itself. 16

Strawson argues that Kant is committed to having actual causal efficacy for the thing in itself. The thing in itself must be the cause of the appearance, or the appearance is not grounded in anything. If the appearance is not grounded in anything, then veridical knowledge must be an

14 Ibid.

15 Ibid.

16 Ibid. 
illusion. 17

We proceed now to a defense of Kant and Kantian philosophy from Strawson's attack. In doing so, one thing is certain: There must be an accounting of Kant's statements which point to transcendental causality. Some of them have been placed earlier in the paper, and there is no doubt that any attack which takes Kant to task for making those statements must be acceptable prima facie. That is to say that when Kant on the one hand puts causality in the categories while, on the other hand stating that the transcendental is somehow the cause of the phenomenal, a problem can certainly be perceived. I will hold that this problem can be overcome, however. To do this it will be imperative to look at two different senses of causality.

Nicholas Rescher provides us with these two types of cause. First, there is authentic causality. By authentic causality, Rescher means the empirical causality which humans observe in the spatial-temporal realm. ${ }^{18}$ So, whenever persons engage in causal judgments-judgments such as perceptions of a game of billiards where it is judged synthetically that the fifteen ball caused the nine ball to move-persons are speaking of authentic causality. Rescher clearly states that this is the causality of which Kant speaks in the Critique of Pure Reason when Kant speaks of causality as only occurring as a result of synthesis through the category of 'cause and effect'.

Rescher establishes the second type of causality as transcendental. Rescher calls this "a not properly causal generic grounding." $19 \mathrm{He}$ holds to the Kantian distinction between 'intelligibility' and 'knowability' by stating that this grounding is intelligible and not knowable. Rescher goes on to say, "The kinship between the two sorts of 'causality' is sufficiently remote that the employment of the same terms — such as 'affecting'—in both cases must be regarded as purely analogical."20

\footnotetext{
17 It seems that Strawson is guilty to committing himself to the Correspondence Theory of Truth. I will not comment on the denial of the Correspondence Theory of Truth that Kant makes other than to say that Kant is correct in asserting that there would be no phenomenal object in the first place (there would only be the thing in itself) if it were not for the human subject. The Copernican Revolution in Philosophy de facto attacks the Correspondence Theory of Truth decisively.

I8 Nicholas Rescher. "Noumenal Causality." Proceedings of the Third International Kant Congress. p.463.

19 "Noumenal Causality." p.463.

20) Ibid.
} 
To defend this assertion that Kant merely uses the idea of transcendental causality in an analogical manner, Rescher quotes Kant ${ }^{21}$ at A206:

“...When I view all things not as phenomena but as things in themselves and as objects of the mere understanding, then despite their being substances they can be regarded, in respect of their existence, as depending upon a foreign cause. But our terms would then carry with them quite other meanings, and would not apply to appearances as possible objects of experience."22

First, we need to understand what Kant means when he asserts that he views all things not as phenomena but as things in themselves. 'Thinghood', for Kant, is only applicable here to the thing in itself. The very term 'appearance' hints that such an object as the apparent object is lacking. What it lacks is what the noumenon has; and that which the noumenon has is 'thinghood'. The phenomenon is what the human subject may know. However, the phenomenon is not the ding-an-sich. The phenomenon is not even a thing per se. At A492, Kant states, “...all appearances...are not in themselves things; they are nothing but representations, and cannot exist outside our mind."23

This said, it is more evident as to what is happening at A206. Kant is claiming that he is allowed to talk of noumena as depending on a foreign cause. At the same time, Kant explicitly warns the reader that the reader should not view the terminology reserved for the thing in itself in the same manner that the reader should view the terminology reserved for phenomenal objects. Otherwise, there will be confusion. This is the confusion which results when a reader hastily regards noumenal causality and phenomenal causality as being identical in terms of causality. At A206, we are cautioned against such a confusion.

This question remains: How are we readers of Kant supposed to justify Kant's assertion that the noumenon has causal efficacy? We are left this question because of A206 and because of numerous other parts of the Critique of Pure Reason which I have provided. All of these quotations

\footnotetext{
21 Ibid.

22 Critique of Pure Reason. A206.

23 Ibid., A492.
} 
point in the same direction. There has to be some way in which the noumenon affects the human subject so that the human subject can do synthesis in order to experience the world. Furthermore, there has to be some way in which the appearance comes to exist. How does that happen? If it is strictly by alteration, then we are still left with the very problem which has been troubling us. In what way do noumena affect phenomena?

Rescher claims that the answer to these problems comes directly from the Principle of Sufficient Reason.24 Kant's own discussion of the Principle of Sufficient Reason in the Critique of Pure Reason is limited. However, we do find that Kant defines it thus:

"The principle of [Sufficient Reason] is this properly...a rule, prescribing a regress in the series of conditions of given appearances, and forbidding [reason] from bringing the regress to a close by treating anything at which [the regress] may arrive as absolutely unconditioned." 25

I take this definition of Kant's to be an explanation of how the phenomenon is ever grounded by the noumenon. When Kant speaks of a series of conditions for given appearances, what does he mean? An example of this is as follows. First, we should gather an idea of some particular appearance. The appearance of a pen will do. Now, any pen will always be a completely phenomenal object. Of course, it seems absurd that anyone should speak of a transcendental pen. Now, since this pen is phenomenal, it is, by definition, conditioned. The human subject has already made a judgment about the world which he or she is experiencing. In this case, the subject has made a seemingly veridical observation. He or she has encountered a pen.

After this is done, the human subject is left to make any number of judgments about the pen. According to the purposes of this paper, let us look to one synthetic and categorical judgment that the subject can makethe judgment of 'cause and effect'. The person will want to know how it is that the pen arrives qua pen. Well, the pen has been empirically caused, we say, by several processes. The people who manufactured the pen take certain materials like plastic, metal, and ink and then put them together in a

24 "Noumenal Causality." p.463.

25 Critique of Pure Reason. A508-A509. 
certain way. The materials of which I speak are not noumenal in the least. This is by definition, because we humans know the materials by which the object is made. So, our regress will continue past the phenomenal objects which make the pen. We shall proceed past the phenomenal objects which make the phenomenal objects (the material which makes material). The regress will approach infinity.

Stopping the regress is precisely the function of the thing in itself. It provides the ground to which the phenomenal object is adherent. Without this ground, persons would be forced into holding to nothing but phenomena. Of course, philosophic history is rich in this discussion of causes, and there are various views on the problems of causality as shown by infinite regress. Kant's solution is that the Principle of Sufficient Reason is what ends the infinite regress. This is precisely what Rescher has in mind:

"A careful heed of this perspective-and so of the distinction between a generic Principle of Sufficient Reason and a specific Principle of Causality-enables us to see how Kant can be freed from the charge of inconsistency in regard to noumenal causality. The answer is simply that the relationship of the thing in itself to the phenomenon is actually not to be construed in causal terms at all. Kant's own occasional looseness of formulation notwithstanding, it is clear that while things in themselves somehow 'affect' the sensibility so as to bring representations of objects into being, the relationship here at issue is definitely not be construed in properly causal terms. The linkage between phenomenon and thing in itself, rather than being actually causal in character, is not mediated by the Principle of Causality at all, but by a more basic and general Principle of Sufficient Reason. This principle is-I submit-the (essentially) non-causal principle of grounding to which Kant time and again makes appeal. And-use of activity-oriented language notwithstanding -an appeal to actual causality is just not at issue here, any more than when one says that 5 is 'produced' by the addition of 3 and 2." 26 
Rescher's assertion is this: The Principle of Sufficient Reason and the Principle of Causality are strictly different notions but are analogically similar notions. The cause and effect relationships that persons observe in the world must adhere strictly with phenomena. This follows from the fact that Kant has asserted that the synthetic judgments that persons make about the world have to necessarily be done with phenomenal objects. This is the case because there is no way in which appearances can be noumenal in character. What is given to the person in the way of experience is already given in space and time. The very setting for experience must necessarily be phenomenal for Kant. However, to say that persons can apply the same concept of the pure understanding or category to a thing in itself would be to contradict the very fact that judgments of cause and effect must be synthetic judgments that are made about appearances.

Rescher's call to the Principle of Sufficient Reason tells the reader that the thing in itself is such that it may provide the ground for the appearance. I go so far as to say that it indeed could be the case that the thing in itself is the cause of appearances. At the same time, the thing in itself may not be the cause of appearances. We cannot know whether the thing in itself is the cause of appearances. This follows from the fact that the thing in itself is not knowable-it is only intelligible. The thing in itself makes appearances possible. However, we cannot know if it is the actual cause of appearances.

There is only one problem with the entirety of the Rescherian position. Rescher seems to claim that the phenomenon and the noumenon are in fact two ontologically distinct entities. Rescher states, "If you are going to claim genuinely objective knowledge, then you must also be prepared to claim a genuine object whose existence at any rate is something independent of the conditions of thought."27 What is implied here is this. There are two numerically distinct entities: the noumenon and the phenomenon. The numerical distinction in the Rescherian position is ontological. I claim, along with Baldner, that this ontological distinction is not necessary. 28 The appearance is truly only the object that is grounded on the thing in itself. The appearance depends upon the thing in itself for its ontological status.

In fact, the ontological status of the phenomenon is zero without the thing in itself. The proof of this contention is given thus: Kant has made

27 Ibid., 467.

28 Kent Baldner. "Causality and Things in Themselves." Synthese. No.77, 1988, pp.354357. 
his claim that the thing in itself is the only entity which has a true claim to the term thing. The appearance is only derivable by the human subject by way of the thing in itself. By the very fact that the appearance has an ontological dependence on the thing in itself, it follows that the appearance is possessive of no ontological dependence without the thing in itself. The thing in itself is the ultimate ontological entity for Kant. Even though it is not knowable, it is still the underlying ' $x$ ' that makes any experience at all possible.

The true difference between the phenomenon and the noumenon is not ontological. It is epistemological. We can know the phenomenon, but we can only think the thing in itself. The noumenon is not knowable strictly because we can never be privy to the unconditioned being. Everything any person knows must, by definition for Kant, be such that it is phenomenal in character. The noumenon is intelligible. It happens to be the ultimate ontological entity, although human beings cannot know it because the very possibility of knowledge is grounded on the categories. The categories can only provide for synthetic judgments on appearances, not things in themselves. Other than on this point, I concur with Rescher's view of transcendental causality.

In conclusion, I refer to other philosophers who have taken the same interpretation on Kant's view of cause and effect. Most recently, Wayne Waxman spoke of the supposed affective agency of things in themselves while Waxman was looking at the Second Analogy.29 Waxman, in a footnote, states, "I can think of no justification consistent with constraints Kant placed on the objective employment of the concept of cause and effect to warrant his use of the manifestly causal notion 'affection' in reference to things in themselves [in the Critique of Pure Reason.]. ${ }^{30}$

Henry Allison has this to say about the problem. "...The problem has been misconstrued.... As traditionally understood, the issue is whether the affecting object is an appearance, a thing in itself, or perhaps both. This formulation is based, at least tacitly, on the assumption that the distinction between appearances and things in themselves is between two kinds of entity."31 I agree with Allison here. There are not two kinds of entity here. There is one entity with full ontological status-the thing in itself. The appearance depends on the thing in itself for its ontological status.

29 "Kant's Analogies." p.97

30 Ibid.

${ }^{31}$ Henry Allison. Kant's Transcendental Idealism. p.248. 
But for Allison, there is still a problem. Allison correctly states that Kant speaks of objects which affect the mind. Are these references to objects as appearances or as things in themselves? 32 I contend that the only objects that can be known to have any causal efficacy are appearances. It is certainly intelligible that the thing in itself could be the cause of appearances, but we can have no knowledge of this according to Kant.

To support my point, I appeal to the examination of the Critique of Pure Reason which Kant undertakes in the Prolegomena to Any Future Metaphysics. I locate the vital discussion of this problem in the Critique of Pure Reason at Paragraph 28 of the Prolegomena:
"...I have no notion of such a connection of things in them- selves, how they can...act as causes.... ...If we should oc- cupy ourselves about the object in itself, there is not a single possible attribute by which I could know that it is deter- mined under [this aspect]...of cause...for I have no con- cept of the possibility of such a connection of existence." 33

This is Kant's own address toward the apparent contradiction that occurs in the Critique of Pure Reason. From this, I claim that Kant had already anticipated the problem.

Responding to the skepticism of David Hume was no easy chore. Hume had sought to destroy the necessary connection of causality, and Hume nearly did destroy it. It was left to Immanuel Kant to save causality from the fires of skepticism, and Kant performed brilliantly. What Kant had to do is part and parcel with his Copernican Revolution in philosophy. Kant had to take the Copernican turn and place 'cause and effect' directly in the categories. In doing so, it was insured that necessary causality was not something that adhered strictly in objects. Necessary causality for Kant adheres neither in the transcendental object nor in the phenomenon. Judgments of necessary cause and effect relationships are, instead, a product of human synthesis. Rational beings are able to take occurrences in the phenomenal realm and then make synthetic judgments about the appearances. So, when a person watches a game of billiards, he or she is able to determine the causal relations that billiard balls have between each other. The billiard balls, as stated before, are phenomenal objects, and persons make

32 Kant's Transcendental Idealism. pp.248-249.

33 Kant. Prolegomena to Any Future Metaphysics. The Carus translation. Paragraph 28. 
judgments synthetically about the causes and effects in a game. Furthermore, persons are able to agree with one another about causal events because persons are all endowed with the same faculties of intuition. Through the intuition (which is the same for all persons) and the affinity of the sensible manifold, we can have a view of causality that is valid for all persons.

There is no transcendental causality that is the same type of causality as is given in the empirical relations of phenomenal objects. This the general position of the Kantian doctrine as Kant saw it in the Prolegomena and as many contemporary philosophers see it.

The noumenal thing is merely the grounding for the phenomenal object. We need this grounding to establish the objectivity of experience. Rescher is quite correct in stating this, but he does go too far in establishing that the noumenon and the phenomenon should be ontologically distinct. All that is necessary is an epistemological distinctness between noumenon and phenomenon. When noumenal causality is viewed as merely analogical, then the problem of the apparent contradiction disappears. Humean skepticism becomes refutable without contradiction.

A very important consideration that has been ignored for the purposes of this paper is the idea of the person as both phenomenon and noumenon. It is clear from Kant's discussion of this ${ }^{34}$ that if we are to deny intelligible causal efficacy for the noumenal self, then we are denying that there can be any practical freedom at all. Kant's discussion of practical freedom comes in the Grounding for the Metaphysics of Morals, and, any important discussion of this notion of practical freedom is beyond the scope of this paper.

\section{WORKS CITED}

Allison, Henry. Kant's Transcendental Idealism. Yale U. Press, New Haven, 1983. Baldner, Kent. "Causality and Things in Themselves." Synthese, No.77, 1988. Dordrecht, Netherlands. pp.353-373.

Kant, Immanuel. Critique of Pure Reason. Translated by Norman Kemp Smith.

St. Martin's Press, New York, 1965.

Prolegomena to Any Future Metaphysics. The Carus Translation. The Bobbs-Merrill Co. Ltd., Indianapolis, 1950.

Rescher, Nicholas. "Noumenal Causality." Proceedings of the Third International

Kant Congress. D. Reidel Co., Dordrecht, Holland, pp.462-470.

Strawson, Peter. The Bounds of Sense. Methuen and Co. Ltd., London, 1966.

Waxman, Wayne. "Kant's Analogies." The Review of Metaphysics. Catholic U. of America, Wash. D.C. Sept. 1993, Vol.47, No.1

34 Critique of Pure Reason. Part III of the Antinomy of Pure Reason. 